Check for updates

The BMJ

Cite this as: BMJ 2021;373:n1292 http://dx.doi.org/10.1136/bmj.n1292 Published: 20 May 2021

\title{
Covid-19: Offer staff military-style mental health support, say healthcare leaders
}

Abi Rimmer

The government should take inspiration from the mental health services offered to veterans when designing services for NHS staff who have worked during the pandemic, leading healthcare organisations have urged.

The call from 13 organisations, including the BMA and several royal colleges, follows research conducted by Neil Greenberg, professor of defence mental health, and colleagues, which showed that NHS staff working in critical care during the pandemic reported more than twice the rate of probable post-traumatic stress disorder (PTSD) than the rate found in military veterans who had recently experienced combat. ${ }^{1}$

In a letter to England's health secretary Matt Hancock, the healthcare organisations acknowledged the government's efforts to improve staff's mental wellbeing through initiatives such as piloting wellbeing hubs and creating a national support service for critical care staff. But they said they feared that some local services might not be continued after the crisis and that longer term treatment for some conditions, including but not limited to PTSD, would not be prioritised.

\section{Key similarities}

"The duration and severity of the covid-19 pandemic has had a huge impact on an already stretched workforce," the letter said. "Many have been dealing with extremely high numbers of critically ill and dying patients, made more challenging by restrictions on family visits.

"Others have been unable to deliver essential care for patients, which has the potential to cause moral injury and mental health disorders. In addition, support and facilities management staff have also been under significant pressure to keep healthcare services functioning."

It added that the NHS's mental health service for veterans, which provides care for veterans who have been psychologically injured because of their service, had helped more than 13 ooo former troops with issues such as anxiety and depression and almost 2000 more with complex problems such as PTSD.

"Despite the difference in context between the military on deployment and healthcare staff working during the pandemic, there are key similarities in terms of the exposure to trauma and risk to psychological and physical health and we have much to learn from the veteran's mental health services," the letter said. "We hope the Government will take inspiration from this when designing services for NHS staff severely impacted by their work during the pandemic."
The letter was signed by:

- The Medical Protection Society

- The Royal College of Psychiatrists

- The Doctors' Association UK

- The Hospital Consultants and Specialists Association

- The BMA

- The Royal College of Surgeons of England

- The Royal College of Surgeons of Edinburgh

- The British Association of Critical Care Nurses

- The Association of Anaesthetists

- The Society of Occupational Medicine

- The Faculty of Intensive Care Medicine

- The British Association of Physicians of Indian Origin, and

- Medical Defence Shield.

Neil Greenberg discusses tackling PTSD in the NHS on The BM/S wellbeing podcast here: https://open.spotify.com/episode/ONIQoayiPm5hhmRcP. ka7KO?si=WwgS-xZXSSqR7_6SrKc_ug.

The military medic Cormac Doyle offers wellbeing lessons from a military perspective on The BM/S wellbeing podcast here: https://open.spotify.com/episode/4yJc7eN5LbkfCKUKCOawSL?si=_TXa3iUpS56SOgZpiX-VHg.

1 Greenberg N, Weston D, Hall C, Caulfield T, Williamson V, Fong K. Mental health of staff working in intensive care during Covid-19. Occup Med (Lond) 2021;71:62-7. doi: 10.1093/occmed/kqaa220.

https://pubmed.ncbi.nlm.nih.gov/33434920/. pmid: 33434920

This article is made freely available for use in accordance with BMJ's website terms and conditions for the duration of the covid-19 pandemic or until otherwise determined by BMJ. You may use, download and print the article for any lawful, non-commercial purpose (including text and data mining) provided that all copyright notices and trade marks are retained. 